\title{
Influence of age on operative mortality and long-term survival after lung resection for bronchogenic carcinoma
}

\author{
M. de Perrot ${ }^{+}$, M. Licker*, M.A. Reymond ${ }^{+}$, J. Robert ${ }^{+}$, A. Spiliopoulos ${ }^{+}$
}

\begin{abstract}
Influence of age on operative mortality and long-term survival after lung resection for bronchogenic carcinoma. M. de Perrot, M. Licker, M.A. Reymond, J. Robert, A. Spiliopoulos. (C)ERS Journals Ltd 1999.

ABSTRACT: The proportion of elderly patients presenting with bronchogenic carcinoma is increasing. To study the impact of age on clinical presentation, management and outcome of patients, the authors have reviewed their clinical experience over the last 20 yrs.

Between 1977 and 1996, 1,079 patients underwent thoracotomy for primary lung carcinoma in the authors' institution. Patients were grouped by age at the time of surgery as $<60$ yrs, $60-69$ yrs and $\geq 70$ yrs.

Although the mode of clinical presentation was similar between all age groups, patients $<60$ yrs were more prone to have advanced stage carcinoma at the time of diagnosis. The rates of exploratory thoracotomy and pneumonectomy were higher in patients $<70$ yrs, whereas lobectomies and lesser resections largely predominated in patients $\geq 70$ yrs. The mortality rate following lobectomy and lesser resection increased from $1.3 \%$ in patients $<60$ yrs to $5.5 \%$ in patients $\geq 60$ yrs $(p=0.04)$ and the mortality rate following pneumonectomy increased from $6.5 \%$ in patients $<60$ yrs to $13.7 \%$ in patients $\geq 70$ yrs $(p=0.24)$. The specific long-term survival, which included only the patients who died from primary lung carcinoma, was similar in all age groups.

Operative mortality and survival rates are acceptable in patients $\geq 70$ yrs. Therefore, age in itself should not constitute a contraindication to surgical lung resection for primary lung carcinoma as long as a careful preoperative assessment is performed to appropriately select surgical candidates.

Eur Respir J 1999; 14: 419-422.
\end{abstract}

'Unit of Thoracic Surgery, Dept of Surgery, and *Division of Anesthesiology, University Hospital of Geneva, Switzerland.

Correspondence: A. Spiliopoulos

Unit of Thoracic Surgery

Dept of Surgery

University Hospital of Geneva

rue Micheli-du-Crest 24

$\mathrm{CH}-1211$ Geneva 14

Switzerland

Fax: 41223727880

Keywords: Age

lung carcinoma

lung surgery

operative mortality

survival

Received: November 21998

Accepted after revision February 71999

Presented at the annual congress of the European Respiratory Society, September 1998, Geneva, Switzerland (Abstract 1866).
As the population becomes older, the proportion of elderly patients presenting with primary lung carcinoma is increasing. Advanced age is considered as a risk factor for lung resection by many authors. However, most of the studies reporting hospital mortality according to patients' ages were performed in the 1970s and early 1980s [1-4]. Although more recent series still report an increased operative mortality in patients $>70 \mathrm{yrs}$, most of them were multicentre studies which included regional medical centres [3-6]. In contrast, other reports dealing with homogeneous groups of patients operated in one single institution and/or by the same surgeon have shown no difference in operative mortality according to age [7-9].

In order to study the impact of age on clinical presentation, management, and outcome, the authors have reviewed their clinical experience over the last 20 yrs.

\section{Materials and methods}

Between January 1, 1977 and December 31, 1996 a total of 1,079 patients underwent thoracotomy for primary lung carcinoma in the authors' institution. The authors retrospectively reviewed all available medical files and nursing charts and extracted data on methods of diagnosis, smoking habits, patients' symptoms, types of surgical procedure, adjuvant therapy, histology and disease stage. Forty-eight patients were excluded from the analysis, 38 due to meta- stasis at the time of surgery (stage IV disease) and nine because of incomplete data. Information on follow-up was obtained from hospital charts, phone calls to family physicians, and examination of the regional cancer registry.

All surgical procedures were performed either by staff surgeons or by senior residents under their direct supervision. The type of resection was primarily dictated by the local extent of the tumour and secondarily by cardiorespiratory function. Resection was macroscopically complete in all patients unless they presented with a stage IIIB tumour $(\mathrm{n}=98)$ or underwent exploratory thoracotomy $(\mathrm{n}=$ 59). Operative mortality included 30-day mortality as well as any later death occurring during the initial postoperative hospital stay. Histological typing was conducted according to the World Health Organization [10] and tumour extent was determined according to the revised primary tumour, regional nodes, metastasis (TNM) classification for all patients [11]. Patients with evidence of mediastinal lymph node involvement underwent chemoradiotherapy and radiotherapy was given if the resection margins were not microscopically tumour-free; lately, chemotherapy has been randomly assigned to patients with regional node (N1) involvement.

As shown in figure 1, the majority of patients undergoing surgery were aged 60-69 yrs. In order to analyse the influence of age on clinical presentation, management and outcome, patients were subsequently divided 


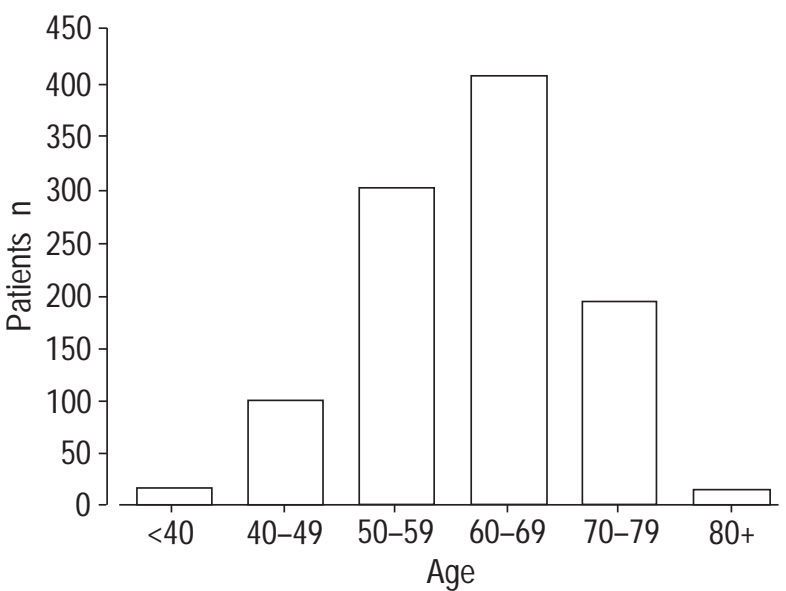

Fig. 1. - Distribution of patients according to their age at the time of surgery.

into three categories according to their age at the time of surgery: 1) <60 yrs $(\mathrm{n}=416,40 \%) ; 2) 60-69$ yrs $(\mathrm{n}=407$, $40 \%)$; and 3$) \geq 70$ yrs $(\mathrm{n}=208,20 \%)$.

\section{Statistical analysis}

Counts were compared with the use of Chi-squared analysis or Student's t-test where necessary. Survival was analysed by the Kaplan-Meier method, and evaluation of the differences was conducted by the log-rank test or logrank test for trend. A p-value $<0.05$ was regarded as statistically significant.

\section{Results}

As described in table 1 , the group of patients aged $\geq 70$ yrs had a significantly greater number of nonsmokers than the other two groups and a higher percentage of females $(21 \%$ of females in age groups $<60$ yrs and $60-69$ $\mathrm{yrs}$, and $29 \%$ of females in age group $\geq 70 \mathrm{yrs}$ ).

Although the mode of presentation was similar between all age groups, patients $<60 \mathrm{yrs}$ were more prone to develop chest pain than older ones, and patients $\geq 70$ yrs

Table 1. - Characteristics of patients by age group

\begin{tabular}{lcccc}
\hline Characteristics & $<60$ yrs & $60-69$ yrs & $\geq 70$ yrs & p-value \\
\hline Patients n & 416 & 407 & 208 & \\
Sex ratio M:F & $4.7: 1$ & $4.8: 1$ & $3.4: 1$ & 0.09 \\
Nonsmoker $^{+}$ & 4 & 6 & 12 & $<0.01$ \\
Clinical signs* & & & & \\
None & 19 & 20 & 25 & 0.24 \\
Haemoptysis & 25 & 29 & 24 & 0.3 \\
Chest pain & 23 & 22 & 14 & 0.04 \\
Weight loss & 25 & 28 & 28 & 0.46 \\
Lung infection & 27 & 21 & 23 & 0.17 \\
Pancoast & 2 & 1 & 0 & - \\
Preoperative diagnosis & & & & \\
Bronchoscopy & 55 & 60 & 55 & 0.28 \\
Needle biopsy & 7 & 6 & 10 & 0.22 \\
Other (sputum exam) & 16 & 17 & 21 & 0.58 \\
No diagnosis available & 22 & 17 & 14 & 0.04 \\
\hline Data aresentedasabsolute
\end{tabular}

Data are presented as absolute numbers for patients (n), sex ratio and p-values; all other data are presented as percentages. +: percentage of patient number for age group; *: symptomatic patients could be reported with more than one clinical sign; *: percentage of patient number for age group. M: male; $\mathrm{F}$ : female. were more frequently asymptomatic than younger ones. Histological diagnosis remained unknown in $22 \%$ of the patients $<60 \mathrm{yrs}$ and in $14 \%$ of the patients $\geq 70 \mathrm{yrs}$.

Squamous cell carcinoma predominated in all age groups, but the proportion of adenocarcinoma was higher among patients $<60$ yrs (table 2).

The proportion of lobectomy and lesser resection was significantly higher and the rate of adjuvant therapy significantly lower in patients $\geq 70$ yrs (table 3 ). These findings were partly related to the higher incidence of early stage carcinomas observed among older patients (table 2). Results of pulmonary function tests did not significantly differ between each age group: the median forced expiratory volume in one second (FEV1) was $86 \%$ of predicted values in patients $<60 \mathrm{yrs}, 75 \%$ pred in patients $60-69 \mathrm{yrs}$, and $80 \%$ pred in patients $\geq 70 \mathrm{yrs}$.

The overall operative mortality was similar between all age groups (table 4). However, the mortality rate following lobectomy and lesser resection increased from $1.3 \%$ in patients $<60$ yrs to $5.5 \%$ in patients $\geq 60 \mathrm{yrs} \mathrm{(} \mathrm{p}=0.04$ ), and the mortality rate following pneumonectomy increased from $6.5 \%$ in patients $<60$ yrs to $13.7 \%$ in patients $\geq 70$ yrs $(p=0.24)$. The main causes of death were pneumonia and respiratory failure in 19 patients, acute cardiac disorders in 12, pulmonary embolus in 10 , haemorrhagic shock in eight, and bronchopleural fistula in seven; no causative factors were identified in 11 patients. No difference was observed between each age group.

In the postoperative follow-up period, causes of death were documented in 686 patients ( $94 \%$ of all deaths). Lung cancer was the primary cause of death in $90 \%$ of the patients who died after pneumonectomy, $85 \%$ after lobectomy and $71 \%$ after segmentectomy. When looking specifically at patients who died from primary lung carcinoma (excluding operative deaths and any other noncancer deaths), the overall long-term survival was similar between all age groups (fig. 2).

\section{Discussion}

In Geneva, Switzerland during the last two decades, the incidence of primary lung carcinoma has largely increased among elderly females (fig. 3), whereas it has remained unchanged in males (fig. 4). Hence, in the current series

Table 2. - Pathological features by age group

\begin{tabular}{lrrrr}
\hline Variable & $<60$ yrs & $60-69$ yrs & $\geq 70$ yrs & p-value \\
\hline Patients $n$ & 416 & 407 & 208 & \\
Histology & & & & \\
Squamous cell & 52 & 58 & 63 & 0.03 \\
Adenocarcinoma & 33 & 29 & 26 & 0.22 \\
Bronchoalveolar & 4 & 4 & 4 & 0.66 \\
Large cell & 7 & 6 & 4 & 0.42 \\
Small cell & 4 & 3 & 3 & 0.64 \\
Stage & & & & \\
IA & 20 & 21 & 17 & 0.37 \\
IB & 25 & 25 & 35 & 0.02 \\
IIA & 4 & 6 & 4 & 0.38 \\
IIB & 18 & 19 & 23 & 0.3 \\
IIIA & 21 & 20 & 14 & 0.11 \\
IIIB & 12 & 9 & 7 & 0.16 \\
\hline
\end{tabular}

Data are presented as percentage of patient number (n) for age group. (except patient number and p-value which are absolute values). 
Table 3. - Surgical and adjuvant therapy by age group

\begin{tabular}{lrrrr}
\hline Variable & $<60$ yrs & $60-69$ yrs & $\geq 70$ yrs & p-value \\
\hline Patients n & 416 & 407 & 208 & \\
Surgery & & & & \\
$\quad$ Thoracotomy only & 8 & 4 & 4 & 0.01 \\
Pneumonectomy & 33 & 31 & 25 & 0.09 \\
$\begin{array}{l}\text { Bilobectomy } \\
\text { Lobectomy and lesser }\end{array}$ & 5 & 7 & 5 & 0.09 \\
$\quad$ resection & & 58 & 66 & 0.02 \\
$\begin{array}{l}\text { Adjuvant therapy } \\
\quad \text { Chemotherapy }\end{array}$ & 9 & 5 & & \\
Radiotherapy & 23 & 20 & 10 & $<0.01$ \\
\hline
\end{tabular}

Data are presented as percentage of patient number (n) by age group for type of surgery, and for adjuvant therapy. Patient number and $\mathrm{p}$-values are given as absolute numbers.

the proportion of females was higher in the group of patients aged $\geq 70$ yrs than in the younger groups.

The overall operative mortality was similar between patients aged $<60$ yrs, 60-69 yrs and $\geq 70$ yrs. Similarly, ROXBURGH et al. [8] and KADRI et al. [9], who respectively reviewed a series of 370 and 479 patients undergoing surgery for primary lung carcinoma, reported a mortality rate of $7 \%$ and $5 \%$ in patients $\geq 70 \mathrm{yrs}$, and of $4.4 \%$ and $4.9 \%$ in patients $<70$ yrs. In contrast to previous series, the current study showed that the operative mortality following lobectomy and lesser resection increased mainly in patients $>60$ yrs of age and remained unchanged thereafter.

The operative mortality after pneumonectomy in patients $\geq 70$ yrs was $13.7 \%$ in the current series. In the literature, the mortality rate after pneumonectomy in patients of the same age varies from $6 \%$ [1] to $21 \%$ [12], but most authors reported a mortality rate between $9 \%$ and $13 \%[8$, 13-15]. These differences in outcome data probably result from variable preoperative risk status, extension of pneumonectomy (radical pneumonectomy and/or resection of thoracic wall versus standard pneumonectomy), and postoperative management. In addition, the definition of operative mortality included alternatively 30-day mortality and in-hospital mortality. In the current series, both 30-day and in-hospital deaths were taken into account.

In contrast to squamous cell carcinoma which was mostly reported in patients $>70 \mathrm{yrs}$, adenocarcinoma was mainly observed in patients $<60 \mathrm{yrs}$. This finding probably resulted from the changing patterns of lung cancer histology over the last 20 yrs. In a previous analysis which included the same group of patients operated on between 1977 and 1996, it was reported that the proportion of females increased from $12 \%$ to $33 \%$ and that of adenocarcinoma from $20 \%$ to $35 \%$ [16]. Changing patterns in

Table 4. - Operative mortality by age group and type of surgery for primary lung carcinoma

\begin{tabular}{lcccc}
\hline & $<60$ yrs & $60-69$ yrs & $\geq 70$ yrs & p-value \\
\hline $\mathrm{n}$ & 416 & 407 & 208 & \\
Overall & 4.8 & 7.9 & 7.2 & 0.19 \\
Pneumonectomy & 6.5 & 11.2 & 13.7 & 0.24 \\
Bilobectomy & 5.9 & 12.9 & 9.1 & 0.74 \\
$\begin{array}{l}\text { Lobectomy and lesser } \\
\text { resection }\end{array}$ & 1.3 & 5.5 & 5.1 & 0.04 \\
\hline
\end{tabular}

Data are presented as percentage of patient number (n) and absolute values for patient number and p-value.

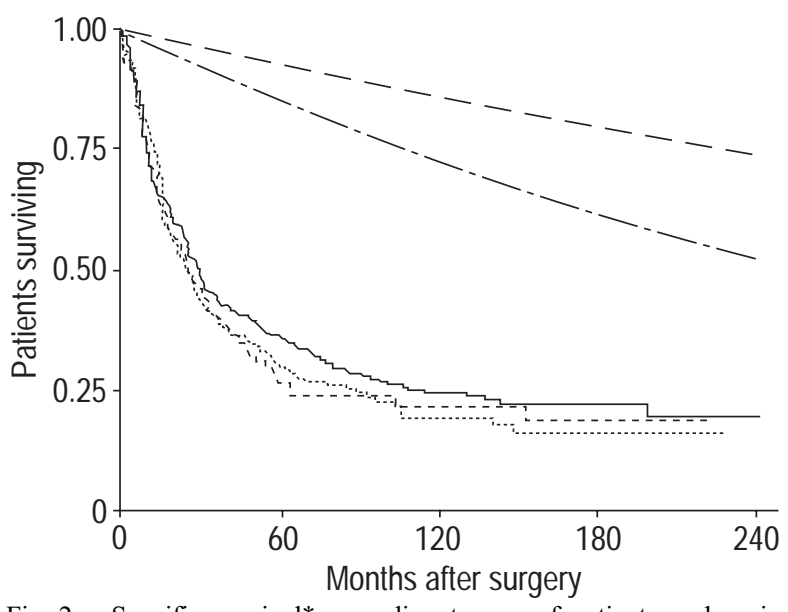

Fig. 2. - Specific survival* according to age of patients undergoing surgery: $-:<60$ yrs $(n=329) ; \cdots: 60-69$ yrs $(n=301) ;-\cdots: \geq 70$ yrs $(n=156)$. Log-rank test for trend between age groups: $\mathrm{p}=0.11$. Survival curves for: age-matched males $(---)$ and females $(---)$ living in Geneva, Switzerland are shown for comparison. *: including only patients who died from primary lung carcinoma.

the female smoking habit have been proposed as a possible explanation for this epidemiological shift [16-18].

The incidence of asymptomatic patients increased with age, from $18 \%$ in patients $<60 \mathrm{yrs}$ to $24 \%$ in patients $>70 \mathrm{yrs}$. Similar observations were reported by NuGENT et al. [19] who showed that the number of asymptomatic patients increased from $9 \%$ in patients $<45$ yrs to $15 \%$ in patients $\geq 80$ yrs. This difference according to patient's age has been attributed to a wider utilization of chest radiographs in the elderly population because of their comorbidities, which has contributed to earlier detection of lung cancer [20]. The presence of clinical signs such as haemoptysis, weight loss and lung infection was similar between each age group. However, similarly to previous reports [4, 19], it was observed that chest pain occurred more frequently in younger patients. This finding correlated with a higher incidence of mediastinal or chest wall involvement due to a more advanced stage of disease [4, 19].

The more advanced stage of disease observed in the youngest group may result from delayed diagnosis due to

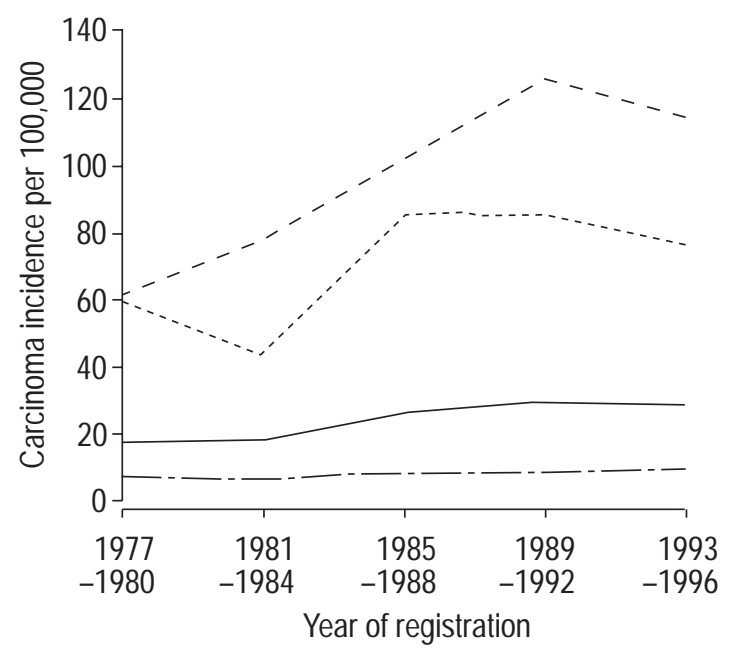

Fig. 3. - The incidence of primary lung carcinoma in females in the canton of Geneva, Switzerland between 1977 and 1996 (data from the regional cancer registry). $---:<60$-yrs-old; - - - : : 60-69-yrs-old; --- : $\geq 70$-yrs-old; - : overall. 


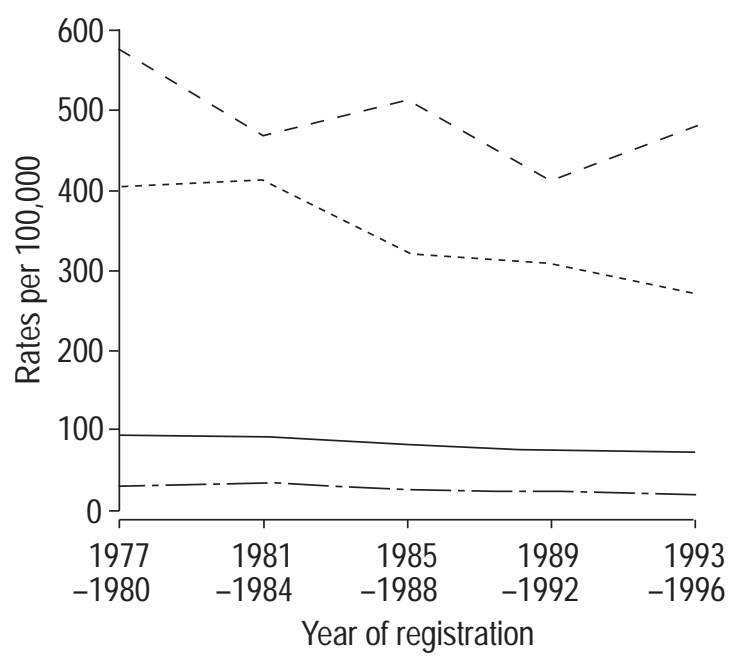

Fig. 4. - The incidence of primary lung carcinoma in males in the canton of Geneva, Switzerland between 1977 and 1996 (data from the regional cancer registry). - - - : <60 yrs old; - - - - : 60-69 yrs old; - - - : $\geq 70$ yrs old: - : overall.

unsuspected lung cancer at a young age. PEMBERTON et al. [21] observed that patients $<40$ yrs of age waited an average of 4.2 months between the onset of symptoms and diagnosis. Similarly, it was found that patients with Pancoast tumours were usually young and often had a delay of several months before the correct diagnosis was made [22]. Therefore, although screening of the general population with chest radiographs has been shown to be inefficient in lowering mortality rates, perhaps it should be restricted to young patients with a heavy smoking history [19, 23].

Surgical strategies are clearly influenced by age and disease stage at presentation. Indeed, pneumonectomies and exploratory thoracotomies were performed more frequently in patients $<60$ yrs, whereas lobectomies and lesser resections largely predominated in patients $>70 \mathrm{yrs}$. This observation was probably related to the greater number of early stage carcinomas observed among older patients. The pulmonary function tests did not significantly differ between each age group and should not, therefore, explain the differences in surgical strategies. In the current series, the exploratory thoracotomy and pneumonectomy rates among elderly patients were higher than the rates reported by other authors [7]. This finding can be explained by the time length of the current study and the higher incidence of exploratory thoracotomy and pneumonectomy $20 \mathrm{yrs}$ ago [16].

The specific long-term survival, which included only the patients who died from lung cancer, was similar between all age groups. Hence, in contrast to other authors who have argued that lung cancer has a less aggressive course in the elderly population, this observation shows that the degree of invasiveness is identical in all age groups [8].

In conclusion, lung resection in patients $\geq 70 \mathrm{yrs}$ is shown to be an acceptable procedure with an overall operative mortality and a long-term survival similar to that of younger subgroups of patients.

\section{References}

1. Ginsberg RJ, Hill LD, Eagan RT, et al. Modern thirty-day operative mortality for surgical resections in lung cancer. J Thorac Cardiovasc Surg 1983; 86: 654-658.
2. Kohman LJ, Meyer JA, Ikins PM, Oates HP. Random versus predictable risks of mortality after thoracotomy for lung cancer. J Thorac Cardiovasc Surg 1986; 91: 551554.

3. Romano PS, Mark DS. Patient and hospital characteristics related to in-hospital mortality after lung cancer resection. Chest 1992; 101: 1332-1337.

4. DeMaria LC, Cohen HJ. Characteristics of lung cancer in elderly patients. J Gerontol 1987; 42: 540-545.

5. Damhuis RAM, Schütte PR. Resection rates and postoperative mortality in 7899 patients with lung cancer. Eur Respir J 1996; 9: 7-10.

6. Wada H, Nakamura T, Nakamoto M, Maeda M, Watanabe Y. Thirty-day operative mortality for thoracotomy in lung cancer. J Thorac Cardiovasc Surg 1998; 115: 70-73.

7. Sherman S, Guidot CE. The feasibility of thoracotomy for lung cancer in the elderly. JAMA 1987; 258: 927-930.

8. Roxburgh JC, Thompson J, Goldstraw P. Hospital mortality and long-term survival after pulmonary resection in the elderly. Ann Thorac Surg 1991; 51: 800-803.

9. Kadri MA, Dussek JE. Survival and prognosis following resection of primary non small cell bronchogenic carcinoma. Eur J cardiothorac Surg 1991; 5: 132-136.

10. World Health Organization. The World Health Organization: histological typing of lung tumors. 2nd Edn. Am J Clin Pathol 1982; 77: 123-136.

11. Mountain CF. Revisions in the international system for staging lung cancer. Chest 1997; 111: 1710-1717.

12. Au J, El-Oakley R, Cameron EWJ. Pneumonectomy for bronchogenic carcinoma in the elderly. Eur $J$ Cardiothorac Surg 1994; 8: 247-250.

13. Wahi R, McMurtrey MJ, DeCaro LF, et al. Determinants of perioperative morbidity and mortality after pneumonectomy. Ann Thorac Surg 1989; 48: 33-37.

14. Patel RL, Townsend ER, Fountain SW. Elective pneumonectomy. Factors associated with morbidity and operative mortality. Ann Thorac Surg 1992; 54: 84-88.

15. Gebitekin C, Gupta NK, Martin PG, Saunders NR, Walker DR. Long-term results in the elderly following pulmonary resection for non-small cell lung carcinoma. Eur J Cardiothorac Surg 1993; 7: 653-656.

16. de Perrot M, Licker M, Robert J, Spiliopoulos A. Time trend in the surgical management of patients with lung carcinoma. Eur J Cardiothorac Surg 1999; 15: 433-437.

17. Zheng T, Holford T, Boyle P, et al. Time trend and ageperiod-cohort effect on the incidence of histologic types of lung cancer in Connecticut, 1960-1989. Cancer 1994; 74: $1556-1567$.

18. Risch HA, Howe GR, Jain M, Burch JD, Holowaty EJ, Miller AB. Are female smokers at higher risk for lung cancer than male smokers?: a case-control analysis by histologic type. Am J Epidemiol 1993; 138: 281293.

19. Nugent WC, Edney MT, Hammerness PG, Dain BJ, Maurer LH, Rigas JR. Non-small cell lung cancer at the extremes of age: impact on diagnosis and treatment. Ann Thorac Surg 1997; 63: 193-197.

20. Salomaa ER, Liippo K, Taylor P, et al. Prognosis of patients with lung cancer found in a single chest radiograph screening. Chest 1998; 114: 1514-1518.

21. Pemberton JH, Nagorney DM, Gilmore JC, Tayor WF, Bernatz PK. Bronchiogenic carcinoma in patients younger than 40 years. Ann Thorac Surg 1983; 36: 509-515.

22. de Perrot M, Licker M, Robert J, Spiliopoulos A. Carcinomes pulmonaires primitifs et syndrome de Pancoast. Schweiz Med Wochenschr 1998; 128: 1548-1552.

23. Strauss GM, Gleason RE, Sugarbaker DJ. Chest X-ray screening improves outcome in lung cancer. A reappraisal of randomized trials on lung cancer screening. Chest 1995; 107: 270S-279S. 